\title{
Study of fish swimming activity using acoustical Doppler velocimetry (ADV) techniques
}

\author{
Ingrid Masaló, Lourdes Reig, Joan Oca* \\ Departament d'Enginyeria Agroalimentària i Biotecnologia, Universitat Politècnica de Catalunya (UPC), \\ Av. Canal Olímpic s/n, 08860 Castelldefels, Spain
}

Received 29 June 2007; accepted 29 October 2007

\begin{abstract}
The suitability of using acoustic Doppler velocimetry (ADV) to study fish swimming activity is evaluated in this study. ADV makes it possible to detect and quantify the relationship between fish density and the turbulence generated by fish swimming activity and to show differences in fish swimming patterns during the scotophase (dark period) and photophase (light period), which has been previously described by other authors. Turbulence was evaluated using the root mean square of velocity (RMS) as an indicator of fish swimming activity, and an ADV probe with an internal sampling rate of $100 \mathrm{~Hz}$, which took 25 velocity data per second.

Experiments at the laboratory scale using zebra fish showed a positive correlation between turbulence (RMS), caused by fish swimming activity, and density. The relationship between density and RMS was strongly linear $\left(r^{2}=0.964\right)$. In an ongrowing farm, daily turbulence patterns caused by fish swimming activity were evaluated with sea bass at two densities: $35.5 \mathrm{~kg} \mathrm{~m}^{-3}$ (average weight of $48 \mathrm{~g}$ ), and $11.8 \mathrm{~kg} \mathrm{~m}^{-3}$ (average weight of $11.7 \mathrm{~g}$ ). Greater activity was detected during the photophase, indicating that light has a substantial affects sea bass swimming activity. Average RMS at a density of $35.5 \mathrm{~kg} \mathrm{~m}^{-3}$ was 3.632 and $2.428 \mathrm{~cm} \mathrm{~s}^{-1}$ during photophase and scotophase, respectively, while working at a density of $11.8 \mathrm{~kg} \mathrm{~m}^{-3}$, average RMS was 1.728 and $1.419 \mathrm{~cm} \mathrm{~s}^{-1}$ during the photophase and scotophase, respectively.

ADV is a rapid and reliable method to evaluate fish swimming activity at laboratory scales as well as at commercial facilities. However, ADV configuration parameters must be properly chosen in order to obtain the highest possible number of good velocity data. Data post-processing was done by filtering velocity data using correlation (COR > 70), signal-to-noise ratio (SNR $>5$ ) and despiking filters. COR provides a measure of quality of each velocity data, ranging from 0 to 100 , and SNR indicates the intensity of the reflected acoustic signal expressed in $\mathrm{dB}$. Finally, despiking filter eliminates spikes generated by fish located near the probe or between the probe and point of measurement. Post-processing showed that COR filter eliminated the higher number of velocity data.
\end{abstract}

(C) 2007 Elsevier B.V. All rights reserved.

Keywords: Fish swimming activity; Acoustic Doppler velocimetry; Turbulence

\section{Introduction}

Studying fish swimming activity is important, not only for understanding fish behaviour, but also for assessing the effects of fish swimming activity on water

\footnotetext{
* Corresponding author. Tel.: +34 935521223; fax: +34 935521001.

E-mail address: joan.oca@upc.edu (J. Oca).
}

homogeneity and sediment dynamics in the tank (Rasmussen et al., 2005; Lunger et al., 2006). From a behavioural perspective, fish activity has traditionally been measured (1) visually (Wagner et al., 1995), (2) via automatically recorded interruptions of infrared light beams set across an aquarium (Iigo and Tabata, 1996; Sánchez-Vázquez et al., 1996), (3) by image processing (Kato et al., 1996) or (4) using acoustic telemetry (Bégout Anras et al., 1997; Bégout Anras and Lagardère, 
1998, 2004; Schurmann et al., 1998; Bauer and Schlott, 2004). However, all these methods are either expensive, intrusive or time consuming, and are only useful when small numbers of fish are being studied.

The effects of fish activity on biosolids sedimentation caused by excretion and uneaten feed are well established. The shear stress due to turbulence generated by fish swimming activity helps prevent biosolids sedimentation and promotes resuspension of biosolids accumulated on the tank bottom. Therefore, the turbulence generated by fish is a valuable parameter for managing biosolids; this parameter will depend on the rearing conditions, such as fish size, density, etc. The relation between the turbulence generated by fish swimming activity and the turbulence needed to resuspend biosolids or prevent their sedimentation is indispensable to predict the existence of self-cleaning conditions in a fish tank.

Fish swim either by body and/or caudal fin (BCF) movements, or by using median and/or paired fin (MPF) propulsion. Pelagic fish swim by $\mathrm{BCF}$ movements, generating a jet of water in the opposite direction to which they are swimming. These jets include a regular pattern formed by vortices shed from fins and tail (Videler, 1993; Müller et al., 1997). In turbulent flow, unsteady vortices appear on many scales and interact with each other. The greater the fish activity, the greater the turbulence generated. Thus, knowledge of fish activity can be obtained by measuring turbulence inside a tank. Turbulence can be expressed as the root mean square (RMS) of the velocity (Wahl, 2006) (Eq. (1)):

$$
\mathrm{RMS}=\sqrt{\frac{\sum_{i=1}^{n}\left(v_{i}-v_{\mathrm{ave}}\right)^{2}}{n}}
$$

where $v_{i}$ represents the instantaneous velocity measurement; $v_{\text {ave }}$ the mean velocity of the flow and $n$ the number of instantaneous velocity measurements. RMS is expressed in velocity units.

In aquaculture tanks there are two sources of turbulence: free shear from the water inflow and friction drag and free shear from fish swimming activity. The hydrodynamics of tanks that do not contain fish have been widely studied (Klapsis and Burley, 1984; Burley and Klapsis, 1985; Cripps and Poxton, 1992, 1993; Oca et al., 2004; Oca and Masaló, 2007; Labatut et al., 2007). The effect of fish presence and the turbulence generated by their swimming activity on the flow pattern has also been studied, but only at the laboratory scale (Burley and Klapsis, 1985; Watten and Beck, 1987; Rasmussen et al., 2005; Lunger et al., 2006).

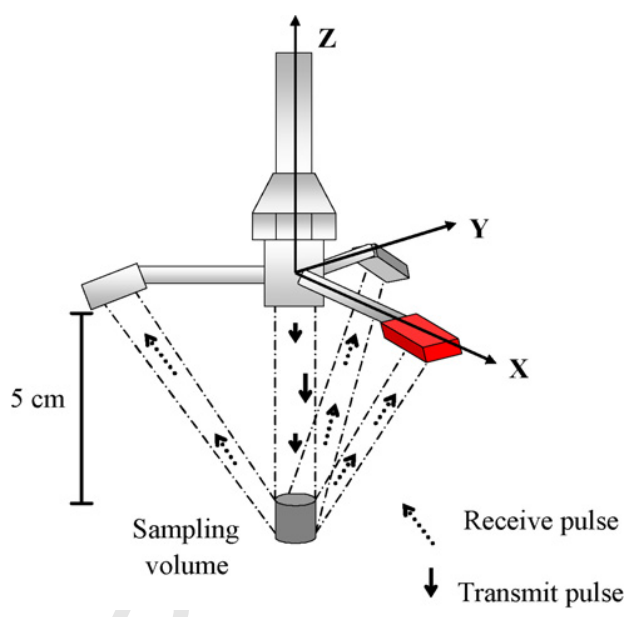

Fig. 1. Diagram of velocity sensor.

Acoustic Doppler velocimetry (ADV) has proven to be a rapid and reliable method for measuring turbulence (Lohrmann et al., 1994; Voulgaris and Trowbridge, 1998). An acoustic Doppler velocimeter is a sensor system based on the acoustic Doppler principle. It is suitable for high-resolution measurements of threedimensional velocities at the laboratory and field scales. The ADV sensor consists of an acoustical signal transmitter and three receivers that are positioned in $120^{\circ}$ increments around the transmitter (Fig. 1). The system operates by transmitting short acoustic pulses of known frequency along the vertical axis. The pulses are propagated through the water, and a fraction of the acoustic energy is scattered back in the sampling volume by small particles suspended in the water (e.g., suspended particles, sediments, small organisms, etc.). The echo from the sampling volume is picked up by the sensor receivers. The frequency shift between the transmitted pulse and the received echo is proportional to the water velocity. Depending on the measurement conditions, ADV configuration parameters (velocity range and sampling volume) must be properly chosen for turbulence measurements, and ADV data should not be used without suitable post-processing (Chanson et al., 2005).

ADV can be a very useful method for measuring turbulence produced by fish activity in laboratory- and commercial-scale tanks in a non-intrusive way, without restrictions concerning the number of fish. This method responds to increasing interest in studying fish swimming movements and behaviour under more natural and less confining conditions using new and innovative techniques and technologies.

The aim of this study is to determine the suitability of acoustic Doppler velocimetry (ADV) for studying fish 
swimming activity and for proposing the signal treatment and data analysis appropriate to evaluating turbulence in tanks containing fish. The relationship between density and the turbulence generated by fish will be tested, and the daily pattern of fish swimming activity in a production tank, with regular lighting periods, will be analysed using the proposed method.

\section{Materials and methods}

Experiments were carried out at the laboratory scale and in an ongrowing farm. A series of experiments at the laboratory scale with zebra fish (Danio rerio) were carried out to study the ability of ADV to detect the presence of fish from RMS measurements and to observe the differences in RMS obtained with different fish densities.

In a commercial aquaculture tank containing sea bass (Dicentrarchus labrax L.) in an ongrowing farm, two series of RMS measurements were taken to assess the turbulence generated by fish swimming activity over time. One series was taken with juveniles (48 g) during a short period of time (approximately $40 \mathrm{~h}$ ) with high density $\left(35.5 \mathrm{~kg} \mathrm{~m}^{-3}\right)$. The second series was taken with smaller fish (11.7 g) for a longer period (approximately 6 days), with low density $(11.8 \mathrm{~kg}$ $\mathrm{m}^{-3}$ ). Experiments were carried out under existing conditions at the facility (photoperiod, water temperature, feeding regime, etc.). The length of the experiments was dependent on farm restrictions.

\subsection{Fish stocking conditions}

\subsubsection{Experiments at the laboratory scale}

Experiments at the laboratory scale were carried out using a circular tank with a diameter of $49 \mathrm{~cm}$ and a water depth of $15 \mathrm{~cm}$. Zebra fish (D. rerio) with a mean body weight of $0.58 \pm 0.12 \mathrm{~g}$, and standard length of $3.12 \pm 0.23 \mathrm{~cm}$ were used. The tank was maintained at a $22.81 \pm 1.53{ }^{\circ} \mathrm{C}$ and under natural photoperiod, with continuously filtered and aerated water (dissolved oxygen above $4.6 \mathrm{mg}^{-1}$ ). Filter and aeration systems were placed outside the working volume to prevent them from affecting the measurements. The bottom of the glass tank was covered with sand to prevent reflecting echoes from the glass bottom being picked up by the receivers, which may occur when the probe is placed near the tank bottom (less than $5 \mathrm{~cm}$ from it) and the bottom is very reflective. A sand layer placed at the tank bottom decreases the percentage of data filtered. Fish were fed once a day at 6 p.m. by means of an automatic feeder.
The water flow was supplied by a vertical pipe placed near the tank wall, with five orifices $(27 \mathrm{~mm}$ in diameter) driving water tangentially to the wall. A water outlet was placed in the centre of the tank bottom in order to achieve a circular flow pattern (Fig. 2). Different densities were tested $(0,1.10,1.27,2.5,3.38$, 7.17 and $7.61 \mathrm{~kg} \mathrm{~m}^{-3}$ ) (Table 1 ).

At each density, five measurements (replicates) were taken. Each measurement was taken at a frequency of $25 \mathrm{~Hz}$ for $20 \mathrm{~s}$, providing a total of 500 velocity data for each measurement (Table 2). This allows us to record frequencies between 0.05 and $12.5 \mathrm{~Hz}$. Test measurements performed during $2 \mathrm{~min}$, allowing us to record frequencies down to $0.0083 \mathrm{~Hz}$, were also performed showing no additional frequency components.

The probe was mounted on a rigid structure which fixed it at the measurement point situated $12 \mathrm{~cm}$ from the tank wall, on the side opposite to the water inlet, and at a mid-water depth $(7.5 \mathrm{~cm}$ from the tank bottom). The $X$-axis for velocity measurements was parallel to the tank wall tangent at the point closest to the wall (Fig. 2). Fish were transferred to the circular tank $48 \mathrm{~h}$ before the measurements were taken. All measurements were taken in the early morning, during photoperiod.

\subsubsection{Experiments in an ongrowing farm}

Experiments were carried out at Méditerranée Pisciculture (Salses le Château, France) in an octagonal $46 \mathrm{~m}^{3}$ tank with a water depth of $167 \mathrm{~cm}$ and a circular flow pattern (Fig. 2). Water flow was supplied with a pipe with multiple orifices placed along the water depth, and a water outlet placed in the centre of the tank. The tank contained European sea bass (D. labrax L.).

Two set of experiments were carried out. The first experiment (Exp. 1) was carried out over a short period of time (approximately $40 \mathrm{~h}$ ), with fish weighing a mean of $48 \mathrm{~g}$, and with a stocking density of $35.5 \mathrm{~kg} \mathrm{~m}^{-3}$ (Table 1). The second experiment (Exp. 2) was carried out during a long period of time (approximately 6 days), with fish weighing a mean of $11.7 \mathrm{~g}$, and with a stocking density of $11.8 \mathrm{~kg} \mathrm{~m}^{-3}$ (Table 1). Fish were exposed to an artificial photoperiod from 9 a.m. to 11 p.m. (lights on between 9 a.m. and 11 p.m.), and fed by means of a self-feeder. Water temperature was maintained at 15 and $22.5{ }^{\circ} \mathrm{C}$ in Exps. 1 and 2, respectively, and salinity maintained at $15 \%$ in both experiments.

Measurements were taken every $5 \mathrm{~min}$ throughout the experiment (Table 2). Each measurement took velocities with a frequency of $25 \mathrm{~Hz}$ for $20 \mathrm{~s}$, and 500 velocity data were obtained. An adaptation period of $48 \mathrm{~h}$, before the data were collected, was set in order to avoid alterations in fish behaviour due to the presence of 

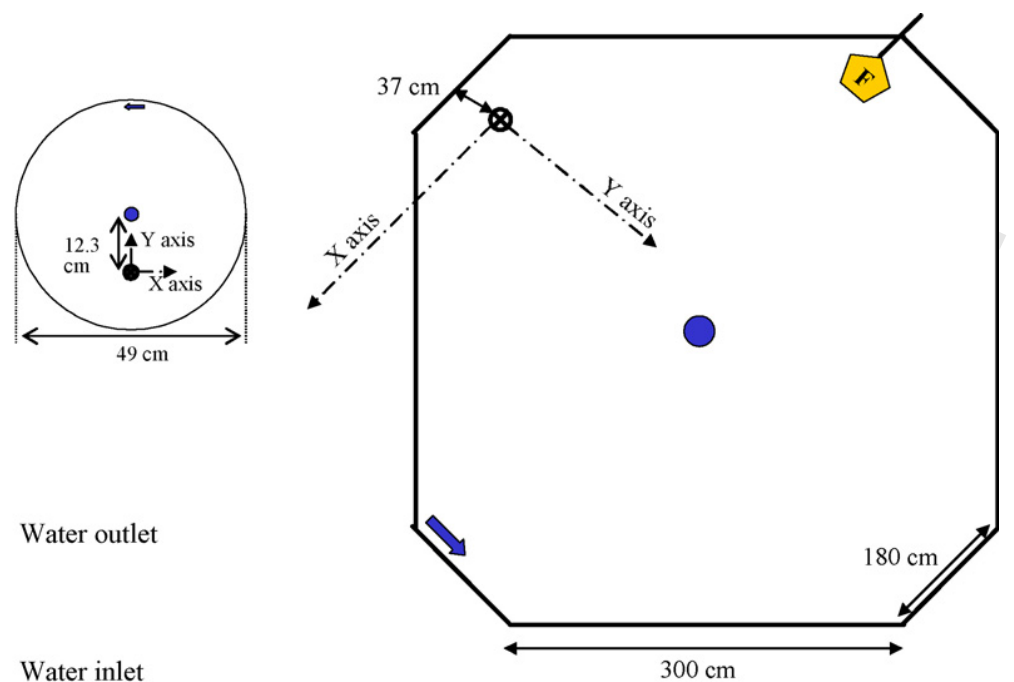

Water inlet

$300 \mathrm{~cm}$

Self feeder

\section{冈 ADV probe}

Fig. 2. Tank description and probe location in experiment with zebra fish (left), and in experiment with sea bass (right).

the probe. The probe was mounted on a rigid structure which fixed it at the measurement point situated at a depth of $85 \mathrm{~cm}$. The $X$-axis for velocity measurements was horizontal and parallel to the tank wall closest to the probe (Fig. 2).

\subsection{Data collection}

The main swimming mode of adult sea bass is BCF (body and/or caudal fin movements). These pattern shows that the velocities in the $X$ - and $Y$-direction (horizontal plane) are the most important (Videler,
1993; Müller et al., 2000, 2002; Nauen and Lauder, 2002), so, in the present study the RMS on the $X$-axis $\left(\mathrm{RMS}_{X}\right)$ is used as the indicator of turbulence generated by fish swimming activity.

Measurements were taken with an ADV sensor by Nortek (Nortek $10 \mathrm{MHz}$ velocimeter); the sampling volume was placed $5 \mathrm{~cm}$ below the probe.

The sensor takes velocity data at an internal sampling rate of $100 \mathrm{~Hz}$ and transmits 100 acoustic pulses per second (100 pings). As the noise in a single ping is too high for practical use, the ADV averages a number of pings before outputting a velocity data. The

Table 1

Fish stocking conditions in each experiment

\begin{tabular}{llll}
\hline & Zebra fish (laboratory) & \multicolumn{2}{l}{ Sea bass (ongrowing farm) } \\
\cline { 3 - 4 } & & Exp. 1 & Exp. 2 \\
\hline Tank volume $\left(\mathrm{m}^{3}\right)$ & 0.03 & 46 & 46 \\
Density $\left(\mathrm{kg} \mathrm{m}^{-3}\right)$ & $0,1.10,1.27,2.5$, & 35.5 & 11.8 \\
& $3.38,7.17$, and 7.61 & & 11.7 \\
Average weight $(\mathrm{g})$ & 0.58 & 48 & 22.5 \\
Temperature $\left({ }^{\circ} \mathrm{C}\right)$ & 22.8 & 15 & 15 \\
Salinity $(\%)$ & 0 & P: 9 a.m. to 11 p.m., & P: 9 a.m. to 11 p.m., \\
Photoperiod & Natural & S: 11 p.m. to 9 a.m. & S: 11 p.m. to 9 a.m. \\
\hline
\end{tabular}

P: photophase (light period) and S: scotophase (dark period). 
Table 2

Velocity data acquisition in each experiment (laboratory with zebra fish, and in an ongrowing farm with sea bass)

\begin{tabular}{|c|c|c|c|}
\hline & \multirow[t]{2}{*}{ Zebra fish (laboratory) } & \multicolumn{2}{|l|}{ Sea bass (ongrowing farm) } \\
\hline & & Exp. $1 \mathrm{bw}: 48 \mathrm{~g}, d: 35.5 \mathrm{~kg} \mathrm{~m}^{-3}$ & Exp. 2 bw: $11.7 \mathrm{~g}, d: 11.8 \mathrm{~kg} \mathrm{~m}^{-3}$ \\
\hline Frequency $(\mathrm{Hz})$ & $25 \mathrm{~s}^{-1}$ & $25 \mathrm{~s}^{-1}$ & $25 \mathrm{~s}^{-1}$ \\
\hline $\begin{array}{l}\text { Number of velocity data } \\
\text { per measurement }\end{array}$ & $500(20 \mathrm{~s})$ (5 replicates) & $500(20 \mathrm{~s})(1$ every $5 \mathrm{~min})$ & $500(20 \mathrm{~s})(1$ every $5 \mathrm{~min})$ \\
\hline Total measurements & 35 & 452 (40 h, approx.) & 1666 (6 days, approx.) \\
\hline
\end{tabular}

bw: body weight and $d$ : fish density.

number of pings averaged for each velocity data provides a specified sampling rate, which can range from 0.1 to $25 \mathrm{~Hz}$. A personal computer conditioned, processed and analysed the shift from the transmitted pulse and the received echo.

The sampling volume is defined by the cylinder formed by the sensor and the perpendicular axis. The diameter of the cylinder is a fixed value $(7 \mathrm{~mm})$. The user can choose a cylinder length of 3,6 or $9 \mathrm{~mm}$. Velocity measurements depend on the echo scattered in the sampling volume, and Nortek AS (2002) recommends choosing the highest sampling volume (9 $\mathrm{mm}$ in length).

In order to obtain a good velocity data, the user needs to take into account the correlation coefficient (COR) and the "signal-to-noise ratio" (SNR).

The ADV computes three correlation values (one for each acoustic receiver). The COR coefficient is a direct output of the Doppler velocity calculations, and provides a quality value for each velocity data, ranging from 0 to 100 . Acceptable COR values are between 70 and 100 (Nortek AS, 2002).

The SNR indicates the intensity of the reflected acoustic signal expressed in $\mathrm{dB}$. Intensity is determined by the concentration and size of the particles suspended in the water. The particles can be naturally occurring, suspended sediments, or artificial ("seeding"). Nortek AS (2002) recommends an SNR above $15 \mathrm{~dB}$ when the user is collecting raw data or above $5 \mathrm{~dB}$ when the user is collecting mean data. No artificial seeding was used in either experiment.

A critical aspect of ADV is the choice of an appropriate velocity range (VR) and sampling volume. As a general rule, the velocity range should always be set as low as possible, because data noise increases with increasing velocity range (the accuracy is $1 \%$ of velocity range at $25 \mathrm{~Hz}$ ). Nevertheless, if the velocity range is set too low, aliasing of the velocity data may occur when velocities exceed the maximum range, causing occasional velocity "spikes" in data. Aliasing occurs when the measured phase difference between the two acoustic pulses transmitted and received by the
ADV exceeds $180^{\circ}$. As the ADV cannot distinguish between a phase difference of $181^{\circ}$ and $-179^{\circ}$, the velocity recorded in the ADV file will change sign, producing a dramatic spike in the velocity data (Wahl, 2000). Aliasing may be generated when the effective distance to the boundary changes during sampling (Schlinder and Robert, 2004) or when there is interference from previous pulses reflected from boundaries with irregular profiles (Dey and Barbhuiya, 2005). In our experiments, aliasing occurred when fish were very close to the sampling volume.

\subsection{Data post-processing}

In the present study, turbulence analysis and postprocessing of raw velocity data were carried out in three steps:

(1) SNR $(>5)$ and COR $(>70)$ were used to check the quality of the velocity data.

(2) A phase-space thresholding technique (despiking filter from Goring and Nikora, 2002) was used to remove spikes produced by aliasing. Nikora and Goring (1998) and Goring and Nikora (2002) developed techniques to eliminate spikes in steady flow situations. The method assumes that good ADV data are clumped within an ellipsoid (defined by a universal threshold $(\sqrt{ }(\ln n \sigma)$, with $n$ representing the number of data and $\sigma$ the standard deviation) in phase-space plot of velocity, $u$, and approximations of the first $(\Delta u)$ and second derivatives $\left(\Delta^{2} u\right)$. Spikes, which will be eliminated, are those points outside of elliptical projection on the ellipsoid onto the three principal phase-space planes $(u-\Delta u$, $\left.\Delta u-\Delta^{2} u, u-\Delta^{2} u\right)$.

(3) Despiking filter has been used in different fields, such as in the study of turbulence in flumes (Biron et al., 2004; Schlinder and Robert, 2004; Dey and Barbhuiya, 2005; Scott et al., 2005) and in the measurement of turbulence in estuaries (Chanson et al., 2005). 
(4) Measurements with less than $50 \%$ of good data (more than $50 \%$ filtered) were removed.

COR, SNR and despiking filter (Steps 1 and 2 in post-processing) were applied using WinADV (Wahl, 2000), a post-processing freeware package designed specifically for the analysis of ADV files. Comparative analyses of COR and SNR filtered data and "despiked" data indicated that most of the spikes are removed by COR filtering (Chanson et al., 2005). Step 3 was applied at each measurement using a spreadsheet.

\section{Results and discussion}

\subsection{Fish swimming activity}

\subsubsection{Experiments at the laboratory scale}

The results show that $\mathrm{RMS}_{X}$ increased with increased densities (from 0 to $7.61 \mathrm{~kg} \mathrm{~m}^{-3}$ ). $\mathrm{RMS}_{X}$ without fish $\left(0 \mathrm{~kg} \mathrm{~m}^{-3}\right)$ had the lowest value $\left(0.213 \mathrm{~cm} \mathrm{~s}^{-1}\right)$, due exclusively to the inflow pattern. When fish were present, $\mathrm{RMS}_{X}$ increased to a maximum value of $0.541 \mathrm{~cm} \mathrm{~s}^{-1}$ at the highest tested density $\left(7.61 \mathrm{~kg} \mathrm{~m}^{-3}\right) . \mathrm{RMS}_{X}$ and density showed a linear relationship with a high correlation $\left(r^{2}=0.964\right)$ (Fig. 3).

The average velocity on the $X$-axis during the experiments was $0.904 \mathrm{~cm} \mathrm{~s}^{-1}$.

\subsubsection{Experiments in an ongrowing farm}

Experiments 1 and 2 showed higher $\mathrm{RMS}_{X}$ values during photophase than during scotophase, as can be seen in Fig. 4. Average $\mathrm{RMS}_{X}$ values measured during photophase in Exps. 1 and 2 were 3.632 and $1.728 \mathrm{~cm} \mathrm{~s}^{-1}$, respectively, while during scotophase, $\mathrm{RMS}_{X}$ values in Exps. 1 and 2 were 2.428 and $1.419 \mathrm{~cm} \mathrm{~s}^{-1}$, respectively.

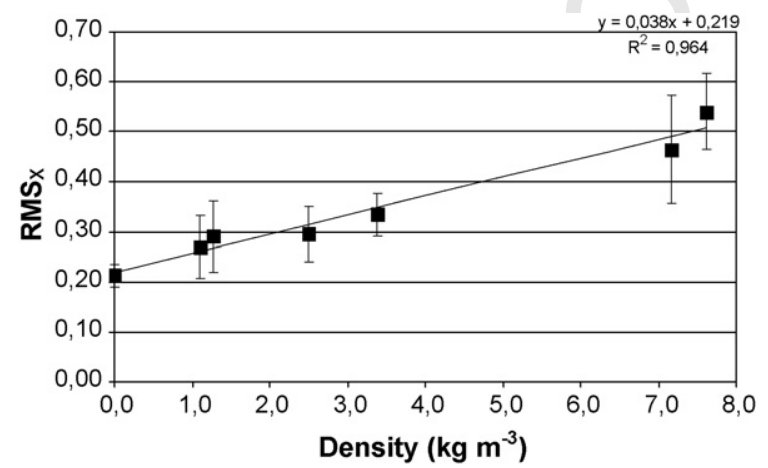

Fig. 3. $\mathrm{RMS}_{X}\left(\mathrm{~cm} \mathrm{~s}^{-1}\right)$ obtained at each density in experiments made with zebra fish.
While it was not possible to measure $\mathrm{RMS}_{X}$ values without fish, $\mathrm{RMS}_{X}$ values during photophase were 1.50 and 1.22 times higher than during scotophase for Exp.1 and Exp. 2, respectively. It is important to remember that the total $\mathrm{RMS}_{X}$ measured is not only due to fish activity, but also to the water current in the tank. Therefore, the above-mentioned ratios would increase if the increase of $\mathrm{RMS}_{X}$ produced by fish was considered in isolation.

Average velocities on the $X$-axis were 12.87 and $13.46 \mathrm{~cm} \mathrm{~s}^{-1}$, respectively, for Exps. 1 and 2.

As expected, a comparison of the two experiments showed greater $\mathrm{RMS}_{X}$ in Exp. 1 than in Exp. 2, as both fish size and density were greater in Exp. 2 (48 g, $\left.35.5 \mathrm{~kg} \mathrm{~m}^{-3}\right)$ than in Exp. $1\left(11.7 \mathrm{~g}, 11.8 \mathrm{~kg} \mathrm{~m}^{-3}\right)$, and average velocities were similar.

An abrupt decrease in $\mathrm{RMS}_{X}$ values was observed every evening when the lights were switched off at 11 p.m. (Fig. 4). When the lights were switched on, $\mathrm{RMS}_{X}$ increased, and the mean value was always higher than the $\mathrm{RMS}_{X}$ obtained during scotophase in both experiments (Table 3 and Fig. 4). Taking a close look at the $\mathrm{RMS}_{X} 1 \mathrm{~h}$ after the lights were switched off, the $\mathrm{RMS}_{X}$ was always lower than the average values obtained during the scotophase (Table 3 and Fig. 5).

Some values above $6 \mathrm{~cm} \mathrm{~s}^{-1}\left(\mathrm{RMS}_{X}>6 \mathrm{~cm} \mathrm{~s}^{-1}\right)$ in Exp. 1, and above $3 \mathrm{~cm} \mathrm{~s}^{-1}$ in Exp. $2\left(\mathrm{RMS}_{X}>\right.$ $3 \mathrm{~cm} \mathrm{~s}^{-1}$ ) (Fig. 4) appeared mainly during light periods (photophase). These values may reflect fish reaction to noise made close to the tank. Experiments were carried out in an ongrowing farm, where staff were working everyday close to the tank and were likely sources of noise. Barnabé (1980) indicated that vibratory disturbances are likely to attract one or more individuals to the source of the vibration, thus generating an increase in turbulence (RMS).

Results obtained in this study concur with findings by Bégout Anras et al. (1997) and Bégout Anras and Lagardère (1998) that show greater activity during photophase. They found sea bass activity to be rhythmic, with fish adopting a diurnal activity rhythm when in a group (60 fishes sizing form 230 to $580 \mathrm{~g}$ ), while single fish were mainly nocturnal. Bégout Anras and Lagardère (1998) described sea bass as a "diurnal and crepuscular" animal.

Similar to Bégout Anras et al. (1997) and Bégout Anras and Lagardère (1998), who determined that light is the dominant factor in the activity of sea bass, our study found that light has a considerable effect on sea bass swimming activity. The impact of light on fish swimming was especially evident when the lights were 

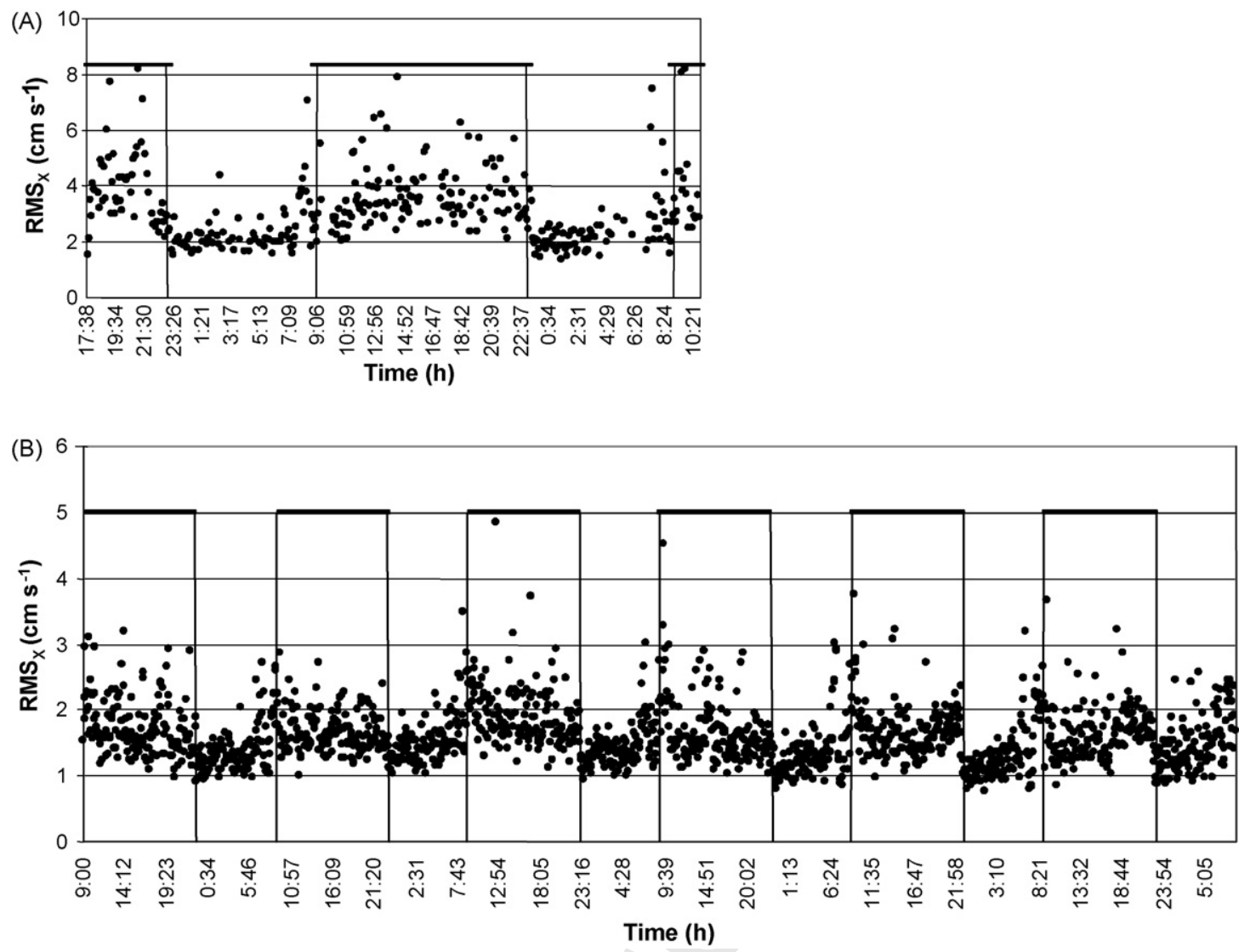

Fig. 4. (A) $\mathrm{RMS}_{X}\left(\mathrm{~cm} \mathrm{~s}^{-1}\right.$ ) during Exp. 1 with sea bass at a density of $35.5 \mathrm{~kg} \mathrm{~m}^{-3}$ (average body weight: $48 \mathrm{~g}$ ). (B) RMS (cm s$^{-1}$ ) during Exp. 2 with sea bass at a density of $11.7 \mathrm{~kg} \mathrm{~m}^{-3}$ (average body weight of $11.8 \mathrm{~g}$ ). Dark horizontal bars represent the light period (photophase).

switched off and a significant decrease in swimming activity was observed. Eriksson (1978) also suggested that light is the main environmental variable affecting rhythmic patterns in fish.

\subsection{Post-processing and data quality}

Data post-processing is important for eliminating low quality velocity data values caused by proximity of fish to probe, or low signal reception. Here, the percentages of data removed in each experiment are presented, together with explanations.

Table 3

$\mathrm{RMS}_{X}$ mean in Exp. 1 (sea bass body weight $48 \mathrm{~g}$, density $35.5 \mathrm{~kg} \mathrm{~m}^{-3}$ ) during photophase $(\mathrm{P})$, scotophase $(\mathrm{S})$, and $1 \mathrm{~h}$ after the lights had been switched off ( $1 \mathrm{~h}$ after off)

\begin{tabular}{lll}
\hline Period & $\begin{array}{l}\mathrm{RMS}_{X}\left(\mathrm{~cm} \mathrm{~s}^{-1}\right) \\
\text { Mean }\end{array}$ & $\begin{array}{l}\mathrm{RMS}_{X}\left(\mathrm{~cm} \mathrm{~s}^{-1}\right) \\
1 \mathrm{~h} \text { after off }\end{array}$ \\
\hline S1 & $2.426 \pm 0.867$ & $1.892 \pm 0.228$ \\
P2 & $3.632 \pm 1.051$ & \\
S2 & $2.430 \pm 0.976$ & $2.144 \pm 0.302$ \\
\hline
\end{tabular}

\subsubsection{Experiments at the laboratory scale}

In experiments at the laboratory scale with zebra fish, measurements had a high mean of good velocity data per measurement $(80.42 \pm 15.44 \%)$, an average correlation of $96.27 \pm 15.10$, and an SNR of $18.58 \pm$

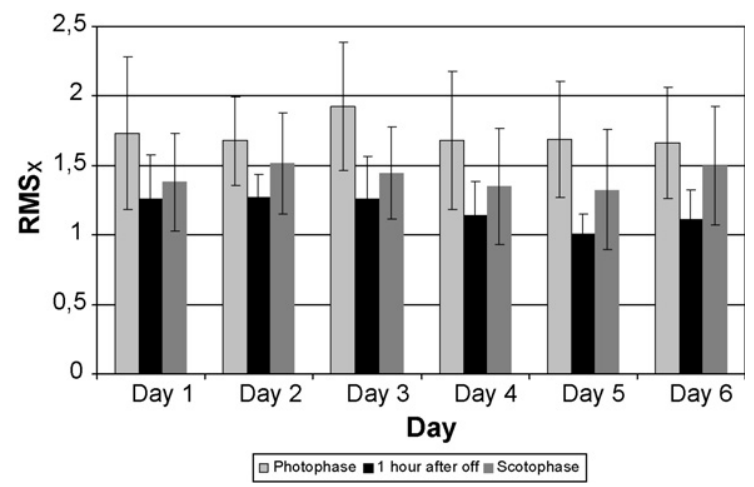

Fig. 5. Mean $\mathrm{RMS}_{X}\left(\mathrm{~cm} \mathrm{~s}^{-1}\right)$ during photophase (light grey), scotophase (dark grey), and $1 \mathrm{~h}$ after the lights were switched off (black) in Exp. 2 with sea bass at a density of $11.7 \mathrm{~kg} \mathrm{~m}^{-3}$ (average body weight: $11.8 \mathrm{~g})$. 
Table 4

Results of data post-processing. bw: body weight, $d$ : fish density

\begin{tabular}{llll}
\hline & Zebra fish (laboratory) & \multicolumn{2}{l}{ Sea bass (ongrowing farm) } \\
\cline { 2 - 4 } & & $\begin{array}{l}\text { Exp. } 1 \mathrm{bw}: 48 \mathrm{~g}, \\
d: 35.5 \mathrm{~kg} \mathrm{~m}^{-3}\end{array}$ & \multicolumn{1}{c}{$\begin{array}{l}\text { Exp. } 2 \mathrm{bw}: 11.7 \mathrm{~g}, \\
d: 11.8 \mathrm{~kg} \mathrm{~m}{ }^{-3}\end{array}$} \\
\hline Valid measurements & 35 of $35(100 \%)$ & 355 of $452(78.5 \%)$ & 1650 of $1666(99 \%)$ \\
Average good velocity data of valid measurements & $80.42 \pm 15.44 \%$ & $66.02 \pm 9.15 \%$ & $81.86 \pm 5.58 \%$ \\
Average COR of good velocity data of valid measurements & $96.27 \pm 15.10$ & $91.89 \pm 2.46$ & $98.59 \pm 1.06$ \\
Average SNR of good velocity data of valid measurements (dB) & $18.58 \pm 4.27$ & $23.58 \pm 6.90$ & $44.57 \pm 5.58$ \\
\hline
\end{tabular}

$4.27 \mathrm{~dB}$ (Table 4). Velocity data elimination was due mainly to COR filtering. None of the 35 measurements taken at the laboratory scale were eliminated due to post-processing. The percentage of data filtered was always lower than $50 \%$.

\subsubsection{Experiments on an ongrowing farm}

In experiments with sea bass raised on an ongrowing farm, the percentage of rejected velocity data was much higher. As a result of post-processing, 97 out of 452 measurements $(21.5 \%)$ in Exps. 1 and only 16 out of 1666 measurements $(<1 \%)$ in Exp. 2 were eliminated (Table 4). Non-rejected measurements had 66.02 \pm $9.15 \%$ good velocity data per measurement in Exp. 1, and $81.86 \pm 5.58 \%$ good velocity data per measurement in Exp. 2, and showed an average correlation of $91.89 \pm 2.46$ and $98.59 \pm 1.06$ in Exps. 1 and 2, respectively. SNR values for Exps. 1 and 2 were $23.58 \pm 6.90$ and $44.57 \pm 5.58 \mathrm{~dB}$, respectively.

Velocity data elimination was mainly due to COR filtering (Step 2 of post-processing). SNR filtering did not eliminate velocity data, as with these densities there were enough particles suspended in the water from fish excretion and uneaten feed.

A higher percentage of measurement elimination in Exp. 1 may have been due to the fact that in Exp. 1 the fish were bigger (48 $\mathrm{g}$ in Exp. 1 vs. $11.7 \mathrm{~g}$ in Exp. 2) and the density higher $\left(35.5 \mathrm{~kg} \mathrm{~m}^{-3}\right.$ in Exp. 1 vs. $11.8 \mathrm{~kg} \mathrm{~m}^{-3}$ in Exp. 2). With larger fish and higher densities there is greater probability of fish getting between the control volume and the receptors, thus producing disturbances in signal reception. For that reason, further experiments should set fish density limits that allow for effective use of ADV techniques to measure turbulence caused by fish swimming activity.

\section{Conclusions}

ADV makes it possible to detect and quantify increases in turbulence caused by fish at different densities and provides a quantitative measurement of swimming activity. Measurement of RMS using ADV techniques has proven to be a rapid and reliable method for quantifying turbulence in a tank containing fish, and shows that turbulence is closely linked to the level of fish swimming activity.

The application of the proposed method in an ongrowing farm allowed a daily cycle of activity among sea bass to be determined and to relate this cycle to photoperiod, obtaining results that are in good agreement with those described by other authors who have studied the behaviour of sea bass.

ADV measurements are very easy to take, require no tank handling or harm to fish, and make it possible to study fish swimming activity with a large number of fish (more than 45,000 in the present study in Exp. 2) in a non-intrusive way. It has been shown that the higher the density, the higher the velocity data eliminated by COR filtering.

Measuring turbulence caused by fish swimming activity can be useful for studying the effect of environmental conditions (photoperiod, temperature, dissolved oxygen, etc.) and rearing conditions (fish density, size, etc.) on fish activity, and for assessing the relationship between fish activity and processes of sedimentation and resuspension of biosolids. A comparative study of turbulence due to fish swimming activity and the turbulence needed to resuspend biosolids would be very useful for determining the rearing conditions necessary to prevent the sedimentation of biosolids and maintain self-cleaning conditions in fish tanks.

\section{Acknowledgements}

This work was funded by the Spanish Ministry of Education and Science (AGL2005-00223-ACU).

The authors would like to extend their thanks to Méditerranée Pisciculture (Salses le Château, France) for the use of their facilities and to M. Conte, in particular, without whom this study would not have been possible. 


\section{References}

Barnabé, G., 1980. Exposé synoptique des données biologiques sur le loup ou bar, Dicentrarchus labrax (Linné, 1758) Synop. FAO Pêches (126) 70, FAO, Rome.

Bauer, C., Schlott, G., 2004. Overwintering of farmed common carp (Cyprinus carpio L.) in the ponds of a central European aquaculture facility - measurement of activity by radio telemetry. Aquaculture 241, 301-317.

Bégout Anras, M.L., Lagardère, J.P., 1998. Variabilité météorologique et hydrologique. Conséquences sur l'activité natatoire d'un poisson marin. C. R. Acad. Sci. 3, Sci. Vie 321 (8), 641-648.

Bégout Anras, M.L., Lagardère, J.P., 2004. Measuring cultured fish swimming behaviour: first results on rainbow trout using acoustic telemetry in tanks. Aquaculture 240, 75-186.

Bégout Anras, M.L., Lagardère, J.P., Lafaye, J.-Y., 1997. Diel activity rhythm of seabass tracked in a natural environment: group effects on swimming patterns and amplitudes. Can. J. Fish. Aquat. Sci. 54, $162-168$.

Biron, P.M., Robson, C., Lapointe, M.F., Gaskin, S.J., 2004. Comparing different methods of bed shear stress estimates in simple and complex flow fields. Earth Surf. Process. Landforms 29, 14031415.

Burley, R., Klapsis, A., 1985. Flow distribution studies in fish rearing tanks. Part 2. Analysis of hydraulic performance of $1 \mathrm{~m}$ square tanks. Aquacult. Eng. 4, 113-134.

Chanson, H., Brown, R., Ferris, J., Ramsay, I., Warburton, K., 2005. Preliminary measurements of turbulence and environmental parameters in a sub-tropical estuary of Eastern Australia. Environ. Fluid Mech. 5, 553-575.

Cripps, S.J., Poxton, M.G., 1992. A review of the design and performance of tanks relevant to flatfish culture. Aquacult. Eng. 11, 7191.

Cripps, S.J., Poxton, M.G., 1993. A method for the quantification and optimization of hydrodynamics in culture tanks. Aquacult. Int. 1, $55-71$.

Dey, S., Barbhuiya, A.K., 2005. Turbulent flow field in a scour hole at a semicircular abutment. Can. J. Civil Eng. 32, 213-232.

Eriksson, L.O., 1978. Nocturnalism versus diurnalism; dualism within fish individuals. In: Thorpe, J.E. (Ed.), Rhythmic Activity of Fishes. Academic Press, London, pp. 69-90.

Goring, D.G., Nikora, V.I., 2002. Despiking acoustic Doppler velocimeter data. J. Hydraul. Eng. 128, 117-126.

Iigo, M., Tabata, M., 1996. Circadian rhythms of locomotor activity in the goldfish Carassius auratus. Physiol. Behav. 60, 775781.

Kato, S., Tamada, K., Shimada, Y., Chujo, T., 1996. A quantification of goldfish behaviour by an image processing system. Research report. Behav. Brain Res. 80, 51-55.

Klapsis, A., Burley, R., 1984. Flow distribution studies in fish rearing tanks. Part 1. Design constraints. Aquacult. Eng. 3, 103-118.

Labatut, R.A., Ebeling, J.M., Bhaskaran, R., Timmons, M.B., 2007. Hydrodynamics of a large-scale mixed-cell raceway (MCR): experimental studies. Aquacult. Eng. 37, 132-143.

Lohrmann, A., Cabrera, R., Kraus, N.C., 1994. Acoustic-Doppler velocimeter (ADV) for laboratory use. In: Proceedings from Symposium on Fundamentals and Advancements in Hydraulic Measurements and Experimentation, ASCE, pp. 351-365.
Lunger, A., Rasmussen, M.R., Laursen, J., McLean, E., 2006. Fish stocking density impacts tank hydrodynamics. Aquaculture 254, 370-375.

Müller, U.K., Van den Heuvel, B.L.E., Stamhuis, E.J., Videler, J.J., 1997. Fish foot prints: morphology and energetics of the wake behind a continuously swimming mullet (Chelon labrosus). J. Exp. Biol. 200, 2893-2906.

Müller, U.K., Stamhuis, E.J., Videler, J.J., 2000. Hydrodynamics of unsteady fish swimming and the effects of body size: comparing the flow fields of fish larvae and adults. J. Exp. Biol. 203, 193-206.

Müller, U.K., Stamhuis, E.J., Videler, J.J., 2002. Riding the waves: the role of the body wave in undulatory fish swimming. Integr. Comp. Biol. 42, 981-987.

Nauen, J.C., Lauder, G.V., 2002. Quantification of the wake of rainbow trout (Oncorhynchus mykiss) using three-dimensional stereoscopic digital particle image velocimetry. J. Exp. Biol. 205, 32713279.

Nikora, V.I., Goring, D.G., 1998. ADV measurements of turbulence: can we improve their interpretation? J. Hydraul. Eng. 124, 630634.

Nortek AS, 2002. Operations Manual Nortek $10 \mathrm{MHz}$ Velocimeter. Nortek AS.

Oca, J., Masaló, I., 2007. Design criteria to obtain rotating flow cells in rectangular aquaculture tanks. Aquacult. Eng. 36, 36-44.

Oca, J., Masaló, I., Reig, L., 2004. Comparative analysis of flow patterns in aquaculture rectangular tanks with different water inlet characteristics. Aquacult. Eng. 31, 221-236.

Rasmussen, M.R., Laursen, J., Craig, S.R., McLean, E., 2005. Do fish enhance tank mixing? Aquaculture 250, 162-174.

Sánchez-Vázquez, F.J., Madrid, J.A., Zamora, S., Iigo, M., Tabata, M., 1996. Demand feeding and locomotor circadian rhythms in the goldfish, Carassius auratus: dual and independent phasing. Physiol. Behav. 60, 665-674.

Schlinder, R.J., Robert, A., 2004. Suspended sediment concentration and the ripple-dune transition. Hydrol. Processes 18, 3215-3227.

Schurmann, H., Claireaux, G., Chartois, H., 1998. Changes in vertical distribution of sea bass (Dicentrarchus labrax L.) during a hypoxic episode. Hydrobiologia 371-372, 207-213.

Scott, C.P., Cox, D.T., Maddux, T.B., Long, J.W., 2005. Large-scale laboratory observations of turbulence on a fixed barred beach. Meas. Sci. Technol. 16, 1902-1912.

Videler, J.J., 1993. Fish Swimming. Chapman and Hall, London, p. 260.

Voulgaris, G., Trowbridge, J.H., 1998. Evaluation of the acoustic Doppler velocimeter (ADV) for turbulence measurements. J. Atmos. Ocean. Technol. 15 (1), 272-289.

Wagner, E.J., Ross, D.A., Routledge, D., Scheer, B., Bosakowski, T., 1995. Performance and behaviour of cutthroat trout (Oncorhynchus clarki) reared in covered raceways or demand fed. Aquaculture 136, 131-140.

Wahl, T.L., 2000. Analyzing ADV data using WinADV. In: Proceedings of the Joint Conference on Water Resources Planning \& Management. Minneapolis, Minnesota, July 30-August 2, 2000.

Wahl, T.L., 2006. WinADV: A Windows-Based Viewing and Postprocessing Utility for ADV Files (Version 2.024). U.S. Department of the Interior, Bureau of Reclamation.

Watten, B.J., Beck, L.T., 1987. Comparative hydraulics of rectangular cross-flow rearing unit. Aquacult. Eng. 6, 127-140. 